\title{
Guided learning at work
}

\section{Stephen Billett}

\author{
Faculty of Education, \\ Griffith University \\ Nathan 4111 \\ Australia
}

Phone (07) 38755855

Fax (07) 38756868

Email s.billett@mailbox.gu.edu.au

Billett S (2000) Guided learning at work, Journal of Workplace learning. 12 (7) 272-285.

\begin{abstract}
This paper reports and discusses the findings of an investigation that examined the efficacy of guided learning in the workplace. The investigation comprised the trialing of guided learning strategies and an analysis of the learning occurring in five workplaces over a period of six months. The guided learning strategies selected for investigation were: (i) questioning dialogues; (ii) the use of diagrams and; (iii) analogies, within an approach to workplace learning emphasising (iv) modelling and (v) coaching. Throughout the investigation, critical incident interviews were conducted to identify the contributions to learning that had occurred during these periods, including those provided by the guided learning. As anticipated, it was found that participation in everyday work activities (the learning curriculum) was most valued and reported as making the effective contributions to learning in the workplace. However, there was also correlation between the reports of the frequency of guided learning interactions and their efficacy in resolving novel workplace tasks, and therefore learning. It is postulated that some of these these learning outcomes where those that could not have been secured by everyday participation in the workplace alone. Further, factors associated with the readiness of enterprise and those within it were identified as influencing the likely effectiveness of guided learning at work.
\end{abstract}

\section{Introduction}

There is growing interest in making workplaces effective learning environments. In turn, this interest demands a clearer understanding of the contributions of these environments and how learning within them might be best realised. This paper reports the findings of an investigation to determine whether guided workplace learning can assist the development of skills and knowledge required for workplace performance. Previous work proposes that participation in everyday work activities make significant contributions to the development of individuals' vocational knowledge (Billett 1993, 1994a, 1994b, 1996, Harris et al 1996, Harris \& Volet 1997). Engagement in authentic workplace activities, and the direct and indirect guidance available in everyday participation in the workplaces were identified as the bases of these contributions. It was concluded from these studies that engagement in everyday activities in the workplace provides ongoing access to goal-directed activities and support that are instrumental in assisting individuals constructing or learning new work-related knowledge as well as the strengthening of that learning (Billett 1999). Also, the contributions of workplace's physical environment provides important clues, cues and models that assist individuals thinking and acting and hence their learning and understanding. Moreover, other workers are used as models for 
performance (albeit in different ways) and as souce of how work tasks should proceed through observations and more direct interactions. Together, it seems, these contributions arising from participation in everyday work activities, assist developing the knowledge required for work performance. Such conclusions are supported by recent theorising (e.g. Hutchins 1993, Resnick, Pontecorvo, Saljo \& Burge 1997) which suggests that knowing (the bases of our thinking, acting and learning) is distributed across social environments, such as workplaces. Therefore, learning is not only ongoing in our everyday thinking and acting, it is mediated by the circumstances in which individuals act.

However, the learning accessed through participation at work alone may not be sufficient for developing the requirements for expertise at work. It was found in these studies, that not all the learning arising from workplace experiences was appropriate, as shortcuts and aspects of inappropriate practices (e.g. dangerous or potentially limiting procedures) were being learnt. Also, it was consistently reported that some of the conceptual knowledge required for workplace performance, particularly that associated with understanding the bases for work tasks, was not being developed. This kind of knowledge is often opaque, hidden or of a kind not readily accessible in the workplace (Billett 1994a, b, Billett \& Rose 1999). Importantly, this kind of conceptual knowledge is increasingly being required for workplace tasks where technological applications are prevalent (Berryman 1993) or where workers are separated from the physical tools and interactions that traditionally have comprised work (Zuboff 1988), thereby making understanding more remote. Examples of this understanding include the way complex systems operate or factors that permit an understanding of phenomena such as force, hygiene, electrical current etc. These types of understanding also permit individuals to innovate and adapt within their domains of activity (Greeno 1989), such as in their vocational practice. However, this kind of knowledge may be difficult to learn without direct guidance that enables it to be made accessible and comprehensible to learners. Similarly, the development of the procedural capacity to successfully complete workplace tasks can also be aided by the direct guidance of more experienced coworkers. Referred to as heuristics or 'tricks of the trade', these procedures provide some certainty of success with vocational tasks. These heuristics evolve through practice over time and are effective tools for workplace performance. For instance, Gott (1989) refers to strategies adopted by avionics technicians in the US airforce who fault-find strategically by checking the easiest to access components and those with a failure profile first, before engaging in a more complete procedure which requires dismantling significant components of the planes. Equally, Orr (1987 cited in Raizen 1991) reports how 'war stories' --- the means by which they have identified, diagnosed and repaired photocopier problems --- are accumulated by experienced photocopy repair technicians as a basis to proceed with their work. These are then used to prepare novice technicians. As heuristics are developed through work practice and over time, they likely require a more experienced co-worker to model their use, explain their purpose and assist novices with their use. Conversely, as noted, there are also outcomes from learning through everyday practice that to be need guarded against. Individuals may learn concepts or procedures that have shortcomings or could even be dangerous (e.g. inappropriate shortcuts) (Billett 1994a, b. Harris et al 1996, Harris \& Volet 1997). Consequently, 
beyond needing to assist making knowledge accessible and mediating the development of understanding and procedures, there is also a need to monitor learning in the workplace to avoid learning through work activities that is inappropriate or even dangerous. These requirements imply that guidance by a more experienced or expert co-worker is needed to mediate what is learnt through engagement in everyday work practice.

Rogoff 's (1995) concept of guided learning proposes an approach that both complements and supplements the contributions to learning through everyday activities in the workplace. The use of selected strategies used within a guided learning approach could support and monitoring the development of the knowledge of workplace learners by making accessible and guiding the development of the kinds of conceptual knowledge that would otherwise remain hidden, yet are salient for effective work practice. As foreshadowed, this type of knowledge is necessary for adaptability --- dealing with non-routine problems such as transferring knowledge from one situation to another (Greeno 1989, Groen \& Patel 1988, Stevenson 1994). As well as having benefits for individuals, in terms of enhancing their vocational practice and its scope of applications, this kind of transferable knowledge is required to enable enterprises to respond to new demands and challenges such as the ever-changing nature of work tasks and dealing with new problems. Often employers' reluctance to develop further the skills of their workforce is premised on concerns of facilitating their employees' mobility --- of assisting them taking those skills to another employer. However, this view overlooks the need for any workforce to be able to respond to the emerging demands. This outcome is unlikely to be achieved by a workforce that lacks robust procedures and understandings that can be applied to the evolving, and sometimes, unpredictable requirements of vocational practice (Berryman 1993). A rich base of transferable knowledge, including conceptual knowledge, in a workplace provides at least one sound basis for enterprises’ survival and growth.

Using these premises, guided learning was adopted as an organising principle for workplace learning interventions that can complement and extend the other contributions to learning vocational knowledge in the workplace. Guided learning here refers to a more experienced co-worker (the mentor) using techniques and strategies to guide and monitor the development of the knowledge of those who are less skilful (the mentees). This approach places the onus on the learner to engage in the thinking and acting required for rich learning. That is, the learners are encouraged and pressed into knowledge constructing and reinforcing activities by the more experienced coworker. Such an emphasis is consonant with propositions about learning within cognitive and sociocultural constructivist perspectives. The engagement in problem solving activities is central to the cognitive perspective's account of how individuals' cognitive structures are extended and reinforced (Anderson 1993). The kinds of problems-solving individuals engage in extend along a continuum of routine (frequently encountered and familiar) to non-routine (new or infrequently encountered), with the degree of routineness being individual dependant. That is, the routine task for one individual may be non-routine to another. The more non-routine the activity, the more likely it will lead to new learning. More routine activities will provide learning through reinforcement that strengthen the organisation of existing knowledge and enhances the confidence with means of proceeding with tasks. The 
sociocultural perspective also accentuates learning through problem solving in goal-directed activities. However, it specifically acknowledges the contributions of a more 'experienced other' in assisting learners' development (Rogoff 1995, Vygotsky 1978). Within both these constructivist perspectives, learners are viewed as active constructors of knowledge, albeit requiring some direction and monitoring from those who are more experienced. However, given the central role that individuals play as meaning makers in these constructive perspectives, it is necessary to accentuate the role played by individuals' interest (Tobias 1994) or dispositions (Perkins, Jay and Tishman 1993) as well as the values that constitute communities of practice (Wenger 1998) such as the particular workplace in which the problem-solving occurs in the context of goal-directed activities and guidance is accessed. These personal and social values guide and direct individuals' focus in and their persistence with thinking, acting and learning (Perkins, Jay \& Tishman 1993). Therefore, these tendencies and the social mores in the workplace will likely contribute to how and in what ways individuals engage in goal-directed activity at work, and as a consequence what vocational knowledge they construct about work.

So in sum, the proposition appraised in the investigation was whether guided learning, through the mediation of the construction of knowledge through expert guidance, offers the kind of interventions capable of complementing and extending the contributions to learning for work provided by engagement in activities in workplaces.

\section{$2 \quad$ Research design and procedures}

A review of the recent literature on mentoring, expertise and the social and cultural contributions to knowledge construction was used to identify the requirements for guided learning in the workplace. From this, a view about guided learning was shaped including approaches to workplace mentoring and the identification of particular learning strategies was developed using relevant literature (e.g. Collins, Brown \& Newman 1989, LeFevre, Greenham \& Waheed 1993, Pea 1993, Smith, Theron \& Anderson 1993). The selection of strategies was premised on the predicted ability to: (i) maximise the potential of the workplace as a learning environment, including redressing the shortcoming identified earlier; and (ii) the ability to be used as part of everyday activities in the workplace. These requirements were held to be salient given that earlier work had consistently identified the contributions of everyday activities in knowledge construction through engagement in authentic workplace activities. More than just convenient and authentic sites for learning, workplaces make active contributions to learning the knowledge required for work. Therefore, interventions need to be embedded in everyday activities, wherever possible, to engage the full range of workplace contributions. Moreover, it is less likely that interventions that which are separate from work practice would be adopted in workplaces given the press on directly productive activities.

The strategies selected for investigation were: (i) questioning dialogues; (ii) diagrams and; (iii) analogies, which were to be deployed within a guided approach to workplace learning emphasising (iv) modelling and (v) coaching. The first three were selected on their predicted ability to 
access and secure conceptual knowledge that might otherwise remain inaccessible (LeFevre, Greenham \& Waheed 1993, Pea 1993, Smith, Theron \& Anderson 1993). The latter two were selected for their potential to develop procedures as well as conceptual knowledge required for the workplace (Collins, Brown \& Newman 1989).

\subsection{Procedures}

The research design comprised two programs of staged inquiry across five workplaces. The first program was a pilot investigation comprising two workplaces with 3 mentors and 4 mentees. It was used to 'de-bug' the mentoring and strategy implementation and data-gathering methods. This second program, which comprised the major investigation included four workplace sites (one of which was in the pilot investigation) and involving 17 mentors and 24 mentees. Differences in functions, products/services and organisational structures comprised the scope of the selected enterprises. They consisted: (i) a food processing company; (ii) a public sector agency associated with social service provisions; (iii) a textile manufacturing company; (iv) a recently corporatised power distribution company; and (v) a small retail business. In each enterprise, the program of trialing guided learning was of six month's duration. Each of these enterprises had quite distinct organisational structures goals, and different levels of readiness to participate in guided learning in the workplace.

In overview, the research procedures sought to gather grounded data about how selected workplace learners (mentees) had learnt over the six-month period. The procedures also aimed to identify the sources of that learning, and, in particular, the role of the guided learning strategies had played in that development. Throughout the six-month period, regular interventions in the form of interviews using 'critical incidents' were conducted. These aimed to identify the sources of learning and associations between the approaches and strategies used and the learning that had occurred during that period.

\section{Preparation of mentors - train-the-mentor program}

The participating enterprises nominated individuals for the guided learning role and also mentees who would be guided by them. The enterprises were requested to select learning guides using a set of selection criteria (e.g. expertise in the work area, ability to interact, willingness to participate). 'Trainthe-mentor workshops' were conducted for all participating mentors. The workshops comprised an overview of the project's goals, an introduction to guided learning and the selected approaches and strategies and their use. In addition, each mentor was given opportunities to consider how these strategies might be applied in their work area. Finally, opportunities were provided to practice and develop the mentors' ability to use these strategies in the relative security of the workshop setting. The workshops were provided on occasions and in locations that meet the participating enterprises' requirements for staff release. Although planned to be of six hours' duration, the workshops were typically only between three and four hours' duration, because of difficulties in gaining the release of enterprise staff. At the workshops, it became evident that the prior knowledge of the project, its aims and the requirements of the mentors were far from uniform across the selected mentors. In extreme 
cases, the participants arriving at the train-the-mentor workshops being uncertain of and suspicious about the basis upon which they had been selected for this role by their enterprise. This was despite prior meetings between the researchers and the enterprises and a detailed information about the project and its requirements being forwarded to each participating enterprise. Follow up visits and other contacts were made by the researchers to help the mentors develop the capacity to conduct their mentoring activities in the workplaces, throughout the six month period. There were differences in the kinds of support required and degree by which support was requested. These ranged from refresher demonstrations to inquiries about using strategies in more elaborate combinations than had been demonstrated at the workshop. Typically, the kinds of support were directly related to the readiness of individuals in conducting the guided learning. Those who had had experience with workplace-based learning were more likely to want to refine and extend their approach further, whereas those from workplaces that lacked such traditions, were more likely to wanted assistance to use the strategies.

Throughout the six-month period, data were elicited from the mentees and mentors at their workplaces. The key emphasis in the data gathering was on the mentees and their learning, through the use of grounded data gathering techniques. This emphasis is consistent with an examination of learning from the constructivist perspectives. It aims to account for the range of contributions to the learners' development that extend beyond those provided by the mentors. However, mentors also provided data about the efficacy of the guided learning approach and the individual strategies. This data gathering involved researchers making regular visits to the workplaces and, observing and interacting with workplace staff which often included others than those directly involved in the project. Through these interactions and regular interviews, the researchers also gained insights into each enterprise and identified factors influencing the implementation of guided learning process. Prior to the commencement of their involvement in the project, both mentors and mentees were informed that the strategies and approaches were under trial, rather than themselves. The procedures for gathering data are described in the following.

\section{Critical incident interviews}

As already noted, a key purpose for the investigation procedures was to identify sources of learning over the six-month period, including links between learning and guided learning interactions. Interviews using 'critical incident' techniques were conducted with the mentees at approximately monthly intervals throughout the program. The approach adopted was modelled on an earlier investigation (Billett 1994a) which used similar procedures to elicit data grounded in actual workplace problem-solving incidents. Interviews were selected as a data-gathering strategy. Given the nature of the work activities, the need to gather data over a long period of time and over a number of workplaces methods such as participant-observation were deemed impractical. However, as the validity of self-reported data is often questioned, the critical incident technique was adopted to ground responses in particular events and situations. It is held that verbal data has greater validity when founded in actual events and changes in behaviour (Ericsson \& Simon 1984). The critical incident 
approach also provides a basis to relate learning to the target work tasks and problems in the workplace, as the incidents are embedded in actual workplace performances.

Accordingly, critical incidents were used to help the mentees to recall and consider three kinds of workplace learning incidents. This approach not only grounded the data in actual workplace incidents, but also focuses the data on problem-solving tasks that were likely to be generative of new knowledge. These were, firstly, 'high moments' - where they had achieved a workplace goal, secondly, 'problem-situations' - how they had responded to workplace problems and, thirdly, 'low moments' - when things had not gone as anticipated in the workplace. Having recounted these events, the participants rated the effectiveness of the contributions of the guided learning strategies, and indirect contributions to learning furnished by the workplace to resolve problems and who or what did they required to resolve the problems comprising the 'low moments'. The contributions to learning presented to the mentees after they had recounted the critical incidents included those identified in earlier studies (Support of mentor, Everyday work activities, Observing and listening to mentor, Observing and listening to others, The workplace and Other workers) and those comprising the guided learning approach. The aim was to understand what had facilitated their learning as captured by incidents linked to non-routine problem-solving. This approach was repeated in each of the four interviews. An interview schedule was used to display questions and capture ratings of the perceived effectiveness of contributions to their learning by rating their efficacy between 1 (low) and 5 (high) in each of the four critical incident interviews. Also, during each of these interviews, the mentees were asked about how frequently each of the interventions had been used in the intervening period.

\section{Final interviews with mentees and mentors}

At the end of the six-month period of trialing in each enterprise, the mentees were asked open questions about their perceptions of the guided learning process. Separately, the mentors were also asked a more exhaustive set of questions to gather perceptions about the mentoring processes' utility. The mentors provided data about their perceptions of the overall effectiveness of the guided learning approach; and then the efficacy of each strategy, in terms of its strengths, weaknesses how it could be improved, as well as predictions about future use. In sum, these data gathering methods aimed to provide grounded and validated data from which conclusions could be drawn about the mentees learning and the contributions of the selected strategies on that learning.

\section{Findings}

The focus of the analysis of the findings presented here is on the contributions to learning across the five workplaces. There were clear differences in the readiness and contributions arising across these workplaces, and in the detail of the data about the efficacy of the guided learning approach and the individual strategies. These are referred to in detail in Billett, McCann and Scott (1988) and are referred to below briefly. However, here the attempt is to draw together the findings across the five sites in order to arrive at some general albeit tentative conclusions about learning at 
work and what role guided learning might play in supplementing other contributions provided by the workplace.

\subsection{Learning at work}

Overall, the findings suggest that everyday participation in work activities made the strongest identifiable contribution to the mentees' learning. This was expected. Earlier work has demonstrated the strength of contributions to learning the knowledge required for work through everyday workplace activities (Billett 1994a, 1996) even when compared with interventions that aimed to 'formalise' workplace learning (Billett 1994b). The strategies selected for this investigation were intended to complement and augment the contributions to learning afforded by everyday participation in the workplace. The data derived from the critical incident interviews (see Table 1) suggest that, as with earlier studies, everyday participation in the workplace is identified as contributing to the development of much of the learning required for workplace performance. However, associations between strategy use and the development of the mentees' knowledge were also identified. A synthesis of these data is presented in Table 1.

In Table 1, data for each mentee was tabulated to aggregate the responses across the four critical incident interviews. The left-hand column indicates the subject (mentee). The columns to the right are divided into two broad headings that categorise two classes of contributions to learning (Utility of the 'learning curriculum' \& Utility of selected strategy and frequency of use). These headings are used to categorise the contributions of responses to everyday participation in the workplace and those of the selected strategies. The aggregation of each mentee's responses under 'Utility of the learning curriculum' - refer to the contributions of Support of mentor, Everyday work activities, Observing and listening to mentor, Observing and listening to others, The workplace and Other workers as identified in earlier work (Billett 1994a, b 1996, Billett \& Rose 1999). Similarly, under the heading 'Utility of strategy and frequency of use are data reported in terms of the contributions of Questioning, Coaching, Analogies, Diagrams and Modelling, about which data on the frequency of their use is also reported. In this table only the frequency of those responses rated 3, 4 and 5 for each mentee (those perceived to have moderate to high levels of usefulness) were aggregated. Aids rated 1 and 2 (of little or no use) were set aside to tighten the data set and cluster those ratings reporting high efficacy. The sum of the frequencies where mentees rated an aid 3, 4 or 5 is reported across each row for each aid to learning. The maximum frequency is 12 (3 incidents in four interviews). Also, to ease analysis, the two highest and lowest frequencies reported by each subject have been highlighted in different ways to assist in discerning patterns of high and low frequency. The two highest scores for each subject are bolded (e.g. 10 9) and the two lowest underlined (e.g. $\underline{0} \underline{1})$.

The frequency for strategy use is indicated by "d" - At least once a day, - "w" - At least once a week, and "m" At least once a month in the columns reporting the efficacy of each strategy. The number of times that the frequencies were reported is shown alongside the lower case letter indicating daily, weekly or monthly use. So, for example, subject A1 reported the contributions of Everyday 
workplace activities (8 frequencies of either 3, 4 or 5) That is, during the critical incident interviews there were 8 instances, out of a possible 12, where everyday workplace activities assisted this person with solving a problem at work. Along with The Workplace (7 frequencies of 3, 4 or 5) these contributions were reported as being of greatest utility in responding to workplace tasks. The subject also rated Questioning, Coaching by mentors, Analogies, Diagram and Modeling with zero frequencies of 3, 4 or 5. Observing and listening to the mentor was rated with once with 3, 4 or 5. In terms of frequency, A1 claimed that, of the strategies deployed by the mentor, Questioning was used at least weekly (w), initially, and then subsequently at least monthly (m). 
Table 1 - Mentees' responses to critical incidents (Billett, McCann \& Scott 1998) Utility of learning curriculum (Billett 1996, Lave 1990)

Utility of strategy and frequency of use

\begin{tabular}{|c|c|c|c|c|c|c|c|c|c|c|c|}
\hline Subject & $\begin{array}{l}\text { Mentor } \\
\text { support }\end{array}$ & $\begin{array}{l}\text { Activit } \\
\text { ies }\end{array}$ & $\begin{array}{l}\text { O\&L } \\
\text { mentor }\end{array}$ & $\begin{array}{l}\text { O \& L } \\
\text { others }\end{array}$ & $\begin{array}{l}\text { Work } \\
\text { place }\end{array}$ & $\begin{array}{l}\text { Other } \\
\text { workers }\end{array}$ & Questioning & Coaching & Analogies & Diagrams & Modelling \\
\hline A1 & 3 & 8 & $\underline{1}$ & 4 & 7 & 2 & $\underline{0}-\mathrm{w} 1 \mathrm{~m} 3$ & $\underline{0}$ & $\underline{0}$ & $\underline{0}$ & $\underline{0}$ \\
\hline A2 & 7 & 11 & 9 & 9 & 6 & 7 & 7 - d2 w2 & $6-\mathrm{d} 1 \mathrm{w} 2 \mathrm{~m} 1$ & $\underline{3}-\mathrm{w} 2 \mathrm{~m} 1$ & $\underline{1}$ & $\underline{3}$ w3 m1 \\
\hline A3 & 10 & 12 & 11 & $\underline{2}$ & 8 & 8 & $9-\mathrm{m} 1 \mathrm{w} 3$ & $10-\mathrm{d} 2 \mathrm{w} 2$ & $\underline{6}-\mathrm{w} 1 \mathrm{~m} 3$ & $8-\mathrm{m} 4$ & $11-\mathrm{d} 4$ \\
\hline A4 & 10 & 10 & 7 & $\underline{5}$ & 9 & 7 & $9-\mathrm{d} 3 \mathrm{w} 1$ & $10-d 4$ & 7 - w3 d1 & $\underline{1}-\mathrm{w} 4$ & $9-\mathrm{w} 1 \mathrm{~d} 2 \mathrm{~m} 1$ \\
\hline A5 & 11 & 12 & 8 & 7 & 9 & 7 & $10-\mathrm{d} 4$ & $6-\mathrm{w} 2 \mathrm{~m} 1 \mathrm{~d} 1$ & $2-\mathrm{m} 2$ & $\underline{1}-\mathrm{m} 1 \mathrm{w} 1$ & $1-\mathrm{m} 2 \mathrm{w} 1$ \\
\hline A6 & 9 & 10 & $\underline{6}$ & 11 & 10 & 8 & $7-d 3 w 1$ & $9-\mathrm{d} 1 \mathrm{w} 3$ & $\underline{2}-\mathrm{w} 3 \mathrm{~m} 1$ & $\underline{2}-\mathrm{w} 1 \mathrm{~m} 2$ & 7 w3 m1 \\
\hline B7 & 7 & 11 & 3 & 2 & 8 & 5 & $3-w 4$ & $3-w 3$ & $\underline{1}-$ & $\underline{0}-\mathrm{w} 1 \mathrm{~m} 1$ & $1-\mathrm{w} 3$ \\
\hline B8 & 7 & 12 & 6 & 10 & 8 & 12 & $7-d 2$ w2 & $\underline{4}-\mathrm{m} 1$ & $6-\mathrm{w} 1 \mathrm{~m} 1$ & $\underline{0}-$ & $5-\mathrm{m} 2$ \\
\hline B10 * & 5 & 4 & 3 & 7 & 4 & 5 & $6-\mathrm{m} 1 \mathrm{w} 1 \mathrm{~d} 1$ & $\underline{2}-\mathrm{m} 1 \mathrm{w} 2$ & $3-\mathrm{m} 1 \mathrm{w} 1 \mathrm{~d} 1$ & $\underline{1}-\mathrm{m} 1 \mathrm{w} 2$ & $5-\mathrm{w} 2$ \\
\hline C11 & 2 & 8 & 2 & 8 & 7 & 9 & $\underline{2}-$ & $\underline{2}$ & $\underline{2}$ & $\underline{0}$ & $\underline{0}$ \\
\hline D16 & 8 & 9 & 8 & 5 & 6 & 4 & $5-\mathrm{d} 2 \mathrm{w} 2$ & $6-\mathrm{d} 2 \mathrm{w} 2$ & $\underline{1}-\mathrm{w} 1 \mathrm{~m} 3$ & $\underline{2}-\mathrm{w} 1 \mathrm{~m} 3$ & $8-w 4$ \\
\hline E17 & 5 & 6 & 1 & 6 & 4 & 6 & $\underline{3}-\mathrm{m} 3 \mathrm{w} 1$ & $\underline{3}-\mathrm{m} 2$ & $\underline{2}-\mathrm{m} 3$ & $\underline{2}-$ & $\underline{2}-\mathrm{m} 4$ \\
\hline E18 & 4 & 6 & 3 & 4 & 1 & 3 & $\underline{0}-\mathrm{w} 1$ & $2-m 2$ & $\underline{0}-$ & $1-$ & 1 - w1 m2 \\
\hline E19 & 3 & 2 & 4 & 6 & 1 & 4 & $\underline{0}-\mathrm{d} 1 \mathrm{w} 2 \mathrm{~m} 1$ & $\underline{1}-\mathrm{m} 2 \mathrm{w} 1$ & $\underline{0}-$ & $\underline{1}-\mathrm{m} 3$ & $\underline{0}-\mathrm{m} 2$ \\
\hline E20 & 5 & 8 & $\underline{4}$ & 8 & 7 & 8 & $\underline{4}-\mathrm{m} 2$ & $\underline{4}-\mathrm{m} 2$ & $\underline{3}-$ & $\underline{4}-\mathrm{m} 1 \mathrm{~d} 1$ & $\underline{4}-\mathrm{m} 2$ \\
\hline E21 & 4 & 10 & 4 & 8 & 8 & 5 & $4-m 1$ & $3-\mathrm{m} 3$ & $\underline{0}-$ & $\underline{1}-\mathrm{w} 1$ & $1-\mathrm{m} 2$ \\
\hline E22 & 2 & 7 & 1 & 4 & 6 & 6 & $1-\mathrm{m} 1$ & $1-\mathrm{m} 1$ & $\underline{0}-$ & $\underline{0}-\mathrm{m} 2$ & $\underline{0}-\mathrm{m} 1$ \\
\hline E23 & 3 & 5 & 5 & 4 & 3 & 4 & 4 - w3 d2 & $\underline{2}-\mathrm{m} 2 \mathrm{w} 2$ & $\underline{0-}$ & $\underline{0-}$ & $3-\mathrm{w} 2 \mathrm{~m} 2$ \\
\hline E24 & 10 & 9 & 9 & 10 & $\underline{4}$ & 8 & $7-d 3$ & 8 - d1 w2 & $5-$ & $\underline{0}-$ & 5 - d1 w1 \\
\hline E25 & 7 & 10 & 7 & 11 & 5 & 8 & $8-d 4$ & $6-\mathrm{d} 3 \mathrm{w} 1$ & $3-\mathrm{w} 1 \mathrm{~m} 2$ & $\underline{0}-\mathrm{m} 2$ & $\underline{2}-\mathrm{d} 2 \mathrm{w} 1$ \\
\hline E26 & 3 & 7 & 3 & 7 & 4 & 6 & $\underline{1}-\mathrm{w} 2$ & $2-w 3$ & $\underline{0}-$ & $\underline{0}-\mathrm{w} 1$ & 3 -w3 d1 \\
\hline E27 & $\underline{2}$ & 5 & $\underline{2}$ & 5 & 4 & 6 & $\underline{1}-\mathrm{d} 1 \mathrm{w} 1 \mathrm{~m} 1$ & $\underline{2}-\mathrm{w} 2 \mathrm{~m} 1$ & $\underline{2}-\mathrm{w} 1 \mathrm{~m} 1$ & $\underline{2}-$ & 2- w3 \\
\hline
\end{tabular}

Note: subject B10 - only three interviews were conducted, no subject B9 existed, subjects C12, C13, C14, C15 were omitted as the data sets were incomplete 
The contributions to securing workplace knowledge of everyday experiences in the workplace, categorised collectively as the 'learning curriculum' were rated higher than the selected guided learning approaches. Everyday activities, Observing and Listening to others and the Workplace were all rated consistently highly, as in the previous study. The support of the Mentor also rated well.

However, there were consistent associations between the frequency of strategy use and perceptions of the utility of those strategies in resolving workplace problems. Put plainly, when the strategies were used frequently, they were reported to be of great utility through the critical incident interviews. Modelling and Coaching were rated quite positively. Of the guided learning strategies selected for trialling, Questioning was reported most frequently used and of high efficacy. Diagrams and Analogies were used less frequently and were less valued. Analogies were found to be difficult for mentors as they required spontaneity with their use. For instance, one mentee reported their mentor straining to find an appropriate analogy for a particular situation. These findings also suggest that some mentors could more readily use some strategies than others and some had a wider perceived utility than others. Importantly, some mentors predicted their ongoing use of these strategies beyond the trial period.

The pattern of associations between the frequency of use and efficacy in terms of contributions to learning through workplace problems is evident in two further tables. In Table 2, data on frequency of strategy use in Table 1 has been aggregated to provide a further use of the quantitative analysis. In the left-hand column, are categorises of frequency of strategy use. In the adjacent rows are reported the number of times (frequency) that strategies were reported as being used either 'at least daily', 'at least weekly' or 'at least monthly' and then the mean (average) of the reported utility and the mode of the utility. What these data indicate is that the more frequent the use of the strategies (e.g. at least daily) the higher their utility is reported and the more likely they are to be individually rated higher.

Table 2 - Reported frequency of strategy use and utility

\begin{tabular}{lccc}
\hline Strategy use & Frequency & $\begin{array}{c}\text { Mean of reported } \\
\text { utility }\end{array}$ & $\begin{array}{c}\text { Mode of reported } \\
\text { utility }\end{array}$ \\
\hline At least daily & 27 & 6.4 & 7 \\
At least weekly & 34 & 2.9 & 2 \\
At least monthly & 20 & 3.1 & 4 \\
\hline
\end{tabular}

The patterning depicted in Table 3 takes this case further by depicting how the data on the reported frequency of 'at least daily' use is correlated with reported utility. The data show that where strategies were used 'at least daily' more frequently (i.e. up to four times) there was likely to be a higher rating of their utility in terms of average and likelihood of high rating. The number of responses here are small, but the pattern identified in the larger data set is maintained. That is probably because the strategies are seen as contributing directly to workplace problems of the kind required for the development of new knowledge in learners. 
Table 3 - Reported frequency of ‘at least daily’ and utility

\begin{tabular}{lccc}
\hline Reported numbers of 'at least daily' & Frequency & Mean & Mode \\
\hline once (d1) & 11 & 4.9 & 3 \\
twice (d2) & 8 & 6.2 & 7 \\
three times (d3) & 4 & 7.3 & 7 \\
four times (d4) & 4 & 9.8 & 10 \\
\hline
\end{tabular}

Therefore, these data suggest that the guided learning at work may be making identifiable contribution to learning, through its augmentation of the activities and guidance that are accessible in the workplace. This contribution can be linked to conceptual development that was identified through the use of concept maps in this study. There was a pattern of association between conceptual development as depicted in the concept maps and the reported efficacy of guided learning in the workplace (Billett, McCann \& Scott 1998). Importantly, this combination of goaldirected activities, being conducted in environments that are authentic in terms of the application of the work-related knowledge are of kinds that cannot be sourced elsewhere.

In sum, the data in Table 1 indicate the reported sources of learning associated with workplace tasks and problem over six-month periods across five workplaces. These data and analysis rate highly the contributions of everyday experiences --- the learning curriculum --- they also depict an association between the frequency of strategy use and their reported utility as depicted further in Tables 2 and 3.

\subsection{Mentors' perceptions of guided learning}

At the end of the six-month period, the mentors were asked in what ways had the mentoring process had been useful, not satisfactory and what improvements are required. The mentors' responses are summarised in Table 4. This table has three columns that are aligned to the questions about the utility, limitations and suggested improvements for the mentoring approach. In this table, the mentors are identified by those the mentored, their mentee(s). For example, the reference to A1 in this table is not the mentee but A1's mentor. Where the mentor has two mentees they are identified by placing a dash to link the mentees (e.g. E26-27).

The utility of the mentoring arrangements were held to include those associated with structuring or 'formalising' a learning process that already occurs 'informally'. This was seen as having benefits for both the mentors and mentees. For the mentors, it pressed the need for some formalisation and structure, presented an opportunity to reflect on practice and furnished a vehicle to interact with workers for the purposes of their development (e.g. induction). For the mentors, the process is seen as engaging them in knowledge constructing activities, advancing discretion to mentees, structuring experiences for them, addressing motivational issues and assisting them to another source of advice. So, the perceived utility of the mentoring program was mainly focused on the learning and the development of both the mentors and the mentees. The need for a thorough 
preparation, monitoring for the mentors and feedback on their performance emerged as a key concern. This was evident in not only gaining competence in the use of the approaches but also changing from other approaches upon which the mentors currently rely. Equally, the lack of initial involvement with mentees in such a program was seen as detrimental to the mentoring process and its outcomes in some work sites. This situation led to some of the mentees being ill at eased or not trusting the process. The mentees also raised these concerns in their feedback.

Table 4- Mentors' perception of the mentoring process (Billett, McCann \& Scott 1998).

\begin{tabular}{|c|c|c|}
\hline Utility & Limitation & Improvements \\
\hline 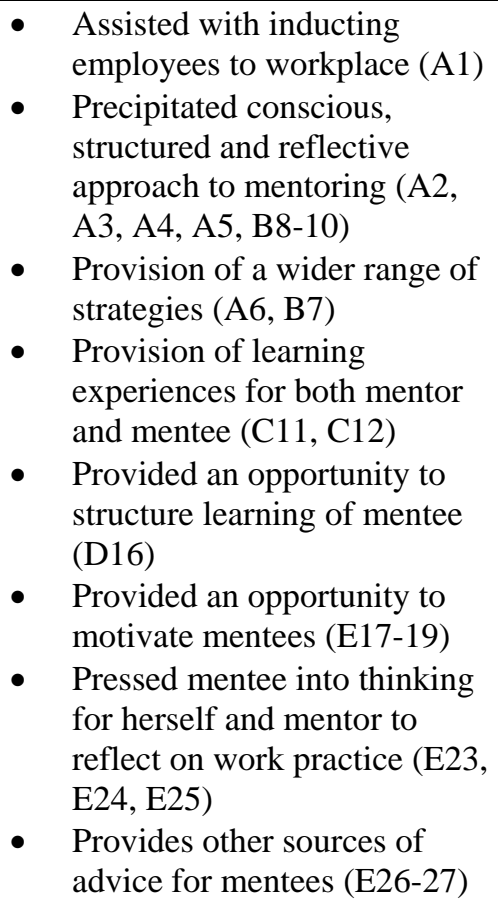 & $\begin{array}{ll}\text { - } & \text { Mainly used for induction } \\
\text { - } & \text { Thrposes (A1) } \\
\text { Specific focus on application } \\
\text { - } & \text { Found it hard to change to } \\
\text { using techniques (A5, B7, B8- } & \text { 10) } \\
\text { - } & \text { Feedback and monitoring } \\
\text { - } & \text { required for mentors (A6) } \\
\text { - } & \text { strategies and access to } \\
\text { - } & \text { Seppertise (B7, C12) } \\
\text { - Time was not the best - not } \\
\text { busy period (E17-19) } \\
\text { - } \quad \text { Unco busy - unprepared (E23) } \\
\text { 27) } \\
\text { Mentees ill at ease with } \\
\text { process (E23) }\end{array}$ & 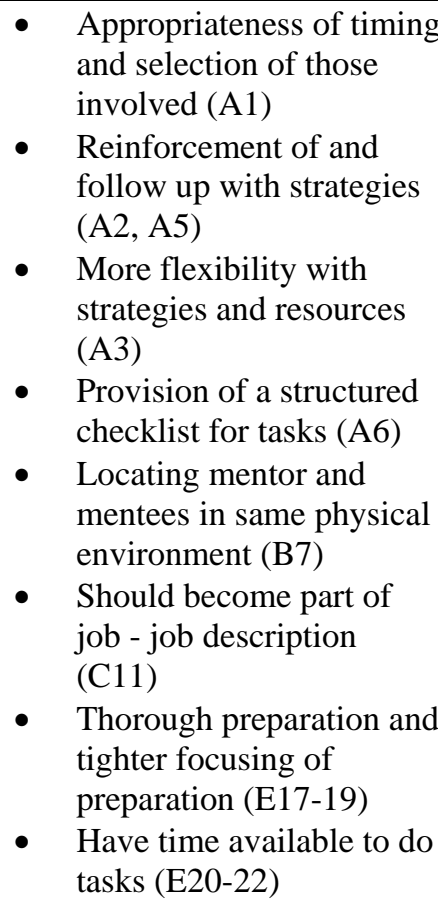 \\
\hline
\end{tabular}

Another key limitation was physical separation of the mentor and mentee. This separation included being in different offices, working in different parts of plant or the enterprise, being in the same location but on different shifts or separation by many kilometres and, hence, infrequent opportunities for face-to-face meetings. In addition, the timing and selection of individuals for mentoring programs was held as a key determinant for some mentors. Timing related to particular periods in production processes, induction of new employees or coincidence with important changes. Considering the factor of proximity in mentoring, it is noteworthy that a number of the mentors at Site A share the same physical environment and probably have the opportunity to meet and discuss their mentoring activities. This situation probably furnishes a form of peer mentoring which is analogous to the 'learning curriculum' referred to earlier.

Each of the strategies was valued in particular ways by the mentors. Questioning was valued as a means to engage learners directly, to get them to do the thinking, to encourage a consideration of options and also as a means to ascertain what the mentees know. Analogies allowed comparison to be made and were perceived to be useful for explaining complex ideas. Diagrams were held to be generative of strong mental images, assist in explaining complex 
concepts and developing understanding. Developing rapport with learners, observation of performance, helping to understand task was reported as being achieved through modelling. Coaching was perceived as help monitor learners' development and assist in their development. Limitations of these strategies were associated with their ease of use and how their use could be integrated into work activities (Billett, McCann \& Scott 1998). In these ways the mentors have provided perceptions of both the general utility of guided approach to learning and the specific strategies.

\section{Discussion}

\subsection{Contributions of everyday activities at work}

The findings reinforce earlier claims that participating in everyday activities in the workplace is a rich source of learning the knowledge required for completing work tasks. Reported under the category of the 'learning curriculum', the data from learners in all five workplaces consistently emphasised the contributions of engagement in everyday activities, and the direct and indirect guidance furnished by social and physical sources within the workplace. Over all subjects and sites, the contributions scoring the four highest frequencies of measures of utility in resolving workplace tasks were Everyday work activities (187), Observing and listening to others (151), Other workers (144) and the Workplace (136). The effectiveness of these components of the 'learning curriculum' (Billett 1996, Lave 1990) appears to be found in its ongoing, ubiquitous and multi-fold contributions. These contributions are ubiquitous in workplaces and exist in ways and at levels that are probably impossible to replicate through instructional interventions or interludes, as they comprise contributions to learning that are embedded in the workplace and in the conduct of work tasks. Taking a constructivist perspective, learning is not separable from thinking and acting. Overcoming disequilibrium (Piaget 1968) and the search for viability (von Glasersfeld 1987) are not restricted to intentional learning within an educational institution, training room, they are part of everyday conscious experiences. It seems that as we think and act we learn. Not all the learning is generative of new knowledge, much of it is strengthening what is already known. Equally, the learning may not be robust or transferable, or even desirable. Nevertheless, through undertaking workplace activities, workers constantly engage in goal-directed activities that are sources of knowledge construction. Depending whether these activities are of a routine or non-routine kind, will determine whether individuals' work-related knowledge is strengthened or extended further.

As identified earlier, and reinforced in this investigation, other and more experienced workers can provide guidance in securing the required workplace goals either directly or indirectly, as does the workplace itself. Indirect guidance can be simply through observing other completed jobs or listening to and observing the activities of others or comprehending the required standards for performance (Lave 1990). It seems that this guidance while not directly intentional, in the instructional sense, nevertheless contributes directly to development of vocational 
knowledge required for performance in those circumstances in which it was engaged. However, there were identified contributions provided by the direct guidance trialled in the investigation.

\subsection{Guided learning at work}

Beyond the contributions of everyday activities, the guided learning strategies selected for this investigation were used to supplement learning through everyday work practice. These strategies are not as readily available or as easy to sustain as the kind of contributions referred to above collectively as the 'learning curriculum'. Nevertheless, the data indicate that the selected strategies made contributions to learning. In conjunction with everyday activities, the use of the selected strategies in the workplace appears to improve the prospect of the development of the kinds of knowledge required for workplace performance. Both mentors and mentees reported that the strategies make particular kinds of contributions. This is most evident in those work sites and those individual instances where the mentors sustained their efforts and frequency of interventions. Frequency of strategy use is also associated with development of conceptual knowledge. Evidence from concept maps and data on strategy use indicated associations between their use and conceptual development. However, the use of the different strategies was more valued by some mentors in some situations, than others and in other situations. To strengthen understandings about the contributions of the selected strategies requires further data to be able to analyse each problem scenario in terms of its conceptual complexity and difficulty to be learnt.

The persistence with some guided learning strategies by mentors over the six-month period was associated with strong perceptions of their utility. It seems unlikely that mentors would have persisted with their use, or learners acknowledge their contributions unless both perceived the utility of these approaches. The perception of utility was supported in other data from the mentors' predictions about their future use.

\subsection{Individual and organisational influences on workplace learning}

The level of strategy utilisation differed across the five workplaces and was far from maximum in all of them. It was reported in the final interviews that a range of factors influenced strategy use. These included the preparedness of the workers selected as guides --- their readiness --- and the organisational structures that inhibited or assisted this development. Each workplace had different goals, procedures, requirements for work performance, and a readiness to participate in guided learning. The importance of the quality of the workplace environment that is conducive to these kinds of interactions is reinforced in this study. Overall, it seems the readiness of the enterprise and its workforces to participate in these kinds of work experiences is the crucial basis for securing the kinds of outcomes desired by workers and enterprises alike. This readiness is founded in organisational factors (e.g. security of employment, openness, trust, existence of expertise) and individuals (both mentors' and mentees') willingness to engage in the effortful process of constructing new knowledge and developing new ways of knowing. For example, in one 
workplace (mentees A2-A6) there was an existing practice of structured workplace training. Here, most of the mentors felt confident about their task and collectively were reported as engaging their mentees in guided learning. They were the mentors that combined the strategies and extended their use. This work area provided the firmest evidence of the persistence in use and their utility. Conversely, in another workplace, there was limited readiness for the mentoring role and considerable reservation by some mentors about the task, and suspicion by a number of the mentees. For example, questioning was perceived by some in this workplace as being an interrogation to determine what the mentees did not know, rather than as a means to assist learning. Nevertheless, one mentor in this workplace persisted with the guided learning and was acknowledge by his mentees as having made a considerable contribution to their learning (see E24/25 in Table 1). The outcomes for these mentees included an enhancing belief in their ability to continue to learn and develop themselves further. So a key outcome was improved self-efficacy for these learners. Conversely, at the workplace previously mentioned that had a history of workplace learning, one mentee (A1) was highly reluctant to engage with his mentor (who was also a peer), despite the best and conscientious efforts of mentor. This led to difficulties in the relationship and the corresponding low frequency of strategy use and reported low level outcome. (see Billett, McCann \& Scott 1998).

The act of engagement in workplace activities is associated with ongoing and constant learning through everyday problem solving, supported and guided by contributions from the workplace. This engagement actively mediates between what the learners currently know with what they encounter through engagement in workplace tasks. So it seems there is rich interdependence between individuals' existing knowledge are variously made vulnerable, transformed or strengthened by these engagements. This interdependence is also energised or deenergised by individuals' interest and commitment to the knowledge to be learnt (Tobias 1994), as evidenced by whether assimilation or accommodation (Piaget 1968) results from such engagements. Vocational practice is likely to be a strong source of interest when embedded in individuals' vocational identity. For instance, whether they engage in learning in a concerted and effortful way.

Therefore, beyond the contributions freely provided in the workplace and those interventions enacted to enhance learning, i.e. the guided learning strategies; individuals' interests will determine how they engage and direct their energies, and persist in goal-directed activities and the quality of the learning that results. So there is a crucial interdependence between the contributions afforded by the social practice of work and individuals' existing knowledge that incorporates their disposition towards particular kinds of learning. Therefore, issues of organisational and individual readiness may well be the basis to explore further improving the outcomes of workplace learning.

\section{Conclusion}


To conclude, findings from this investigation support earlier studies by re-emphasising the contributions of engagement in goal-direct workplace activities, and the direct and indirect forms of guidance that assist individuals resolve workplace problems, thereby developing further their work-related knowledge. These contributions collectively are referred to as the workplace learning curriculum, following Lave (1990). Other tentative findings suggest that the guided learning strategies augment these contributions by providing particular contributions that are not realised through mere participation at work. These conclusions were drawn from analyses of data drawn from five workplaces with different organisational structures, work roles and familiarity with workplace training. However, whereas the findings about everyday activity were sustained uniformly across their workplaces, the reported contributions of guided learning differed across, and within the workplaces. The findings about individuals and organsational readiness and the different requirements for guided learning at work suggest that preparation may be required for establishing a workplace curriculum in each workplace. This is likely to extend to the preparation of mentors, selection of strategies, briefing the learners and also identifying goals for workplace learning. Monitoring of and ongoing support for the development of guided learning skills in the workplace will probably be needed.

From this study and earlier work, some bases to advance a workplace curriculum or pedagogy of the workplace are identifiable in terms of the integration of everyday learning experiences and guided learning strategy use. The shape and development of that pedagogy are likely to be a product of the unique requirements and needs of each workplace. It seems that the readiness of the organisation and its workers encompass key factors that will determine the shape and form of such learning arrangements, including their level of sophistication and scope of the intended outcomes. So although the evidence provided by the investigation about the contributions of everyday participation and guided learning assists working towards refining workplaces as learning environments their potency will be premised on the factors at the workplace level. It is these that will likely determine how workplace learning will proceed and the quality of its outcomes.

Acknowledgements. Research assistance was ably provided by Kerrie Scott and Andrew McCann from the Wodonga Institute of TAFE. Thanks to the enterprises and individuals in those enterprises who made this research project possible. Also, the National Research and Evaluation Committee of ANTA who funded this study. Also, the comments of the two anonymous reviewers were helpful in refining this paper and posing questions that will guide further inquiry.

\section{References}

Anderson, J. R. (1993). Problem solving and learning. American Psychologist, 48 (1), 35-44.

Berryman, S. (1993). Learning for the workplace. Review of Research in Education, 19, 343-401.

Billett, S. (1998). Understanding workplace learning: Cognitive and sociocultural perspectives. In D. Boud (ed) Current Research and New Agendas in Workplace Learning (pp.47-68). Adelaide: National Centre for Vocational Education Research., Adelaide, ISBN 0873974700

Billett, S. (1996). Towards a model of workplace learning: the learning curriculum. Studies in Continuing Education. 18 (1) pp.43-58.

Billett, S (1994a). Situated Learning - a workplace experience. Australian Journal of Adult and Community Education, 34 (2) 112-130. 
Billett, S. (1994b). Authenticity in workplace learning settings. In J. C. Stevenson (Ed) Cognition at work: the development of vocational expertise. (pp. 36-75).Adelaide: National Centre for Vocational Education Research.

Billett, S (1993). What's in a setting - learning in the workplace. Australian Journal of Adult and Community Education, 33 (1) April 1993. 4-14

Billett, S, McCann, A \& Scott, K (1998) Workplace mentoring: Organising and managing effective practice. Centre for Learning and Work Research, Griffith University. ISBN 0868579149

Billett S \& Rose J (1999). Securing conceptual knowledge in the workplace. In P Murphy (ed.) Learners' Learning and Assessment. Sage Publications: London (pp.329-344).

Chi, M. T. H., Glaser, R., \& Farr, M. J (1982). The nature of expertise. Hillsdale, NJ:Erlbaum.

Collins, A., Brown J. S., \& Newman, S. E. (1989). Cognitive apprenticeship: teaching the crafts of reading, writing and mathematics. In L.B. Resnick, (ed) Knowledge, learning and instruction, essays in honour of Robert Glaser. (pp. 453-494). Hillsdale, N.J: Erlbaum \& Associates.

Ericsson, K. A., \& Simon, H. A. (1984). Protocol analysis - verbal reports as data. Cambridge, Mass. MIT Press

Gott, S (1989) 'Apprenticeship instruction for real--world tasks: The co-ordination of procedures, mental models, and strategies' Review of research in education ed. E.Z. Rothhopf American Educational Research Association, Washington, DC

Greeno, J. G. (1989). Situations, mental models, and generative knowledge. In D. Klahr \& K. Kotovsky (eds). Complex information processing: The impact of Herbert A. Simon. Hillsdale, New Jersey: Erlbaum.

Groen, G. J., \& Patel, P. (1988). The relationship between comprehension and reasoning in medical expertise. In M. T. H. Chi, R. Glaser and R. Farr, The Nature of Expertise. New York: Erlbaum.

Harris, R, Simons M, Willis, P \& Underwood, F 1996b, ‘Pandora’s Box or Aladdin's Cave: What can on and off-job sites contribute to trainees' learning? Vol 2 of the proceedings of Learning and Work: The challenges - 4th Annual International Conference on Post-Compulsory Education and Training pp 719.

Harris L \& Volet S, (1997) `Developing a learning culture in the workplace’, Murdoch University, Western Australia.

Hutchins, E. (1993) 'Learning to navigate’ Understanding practice: Perspectives on activity and context Eds S. Chaiklin \& J. Lave (pp. 35--63), Cambridge University Press, Cambridge, UK

Lave, J. (1990). The culture of acquisition and the practice of understanding. In J. W. Stigler, R. A. Shweder \& G. Herdt (eds). Cultural psychology (pp. 259-86). Cambridge. U.K: Cambridge University Press.

LeFevre, J-A, Greenham, S L \& Waheed, N (1993). The development of Procedural and Conceptual Knowledge in Computational Estimation. Cognition and Instruction, 11 (2) 95-132.

Pea, R D (1993). Learning scientific concepts through material and social activities: conversational analysis meets conceptual change. Educational Psychologist, 28 (3) 265-177.

Perkins, D., Jay, E. \& Tishman, S. (1993). Beyond abilities: A dispositional theory of thinking. Merrill-Palmer Quarterly, 39 (1), 1-21.

Piaget, J. (1968). Structuralism. (C. Maschler, trans. and ed.) London: Routledge and Kegan Paul.

Raizen, S A. (1991) Learning and Work: the research base Paris: OECD

Resnick L B, Pontecorvo C, Saljo R \& Burge B (1997) - Introduction - In LB Resnick, C Pontecorvo \& R. Saljo (eds) Discourse, tools and reasoning: Essays on Situated Cognition. Springer, Berlin (pp. 120).

Rogoff, B (1995). Observing sociocultural activity on three planes: Participatory appropriation, guided participation, apprenticeship. In J W Wertsch, A Alvarez \& P del Rio, (Eds). Sociocultural studies of mind (pp 139-164). Cambridge: Cambridge University Press.

Smith, E L, Theron, D, \& Anderson, C W (1993). Teaching strategies associated with conceptual change learning in science. Journal of research in science teaching, 30 (2) 11-126.

Stevenson J C (1994) 'Vocational Expertise' Cognition at work: The development of vocational expertise ed. J. Stevenson (pp. 7--35). National Centre for Vocational Education Research, Adelaide, South Australia

Tobias, S. (1994). Interest, prior knowledge, and learning. Review of Educational Research, 64 (1), 37-54.

von Glasersfeld, E. (1987) 'Learning as a constructive activity’ Problems of representation in the teaching and learning of mathematics. ed. C. Janvier Lawrence Erlbaum, Hillsdale, New Jersey

Vygotsky, L. S. (1978). Mind in society - the development of higher psychological processes. Cambridge: Harvard University Press.

Wenger E (1998) Communities of practice: Learning, meaning, and identity. Cambridge: Cambridge University Press.

Zuboff S (1988) In the age of the smart machine: The future of work and power. New York: Basic Books. 